\title{
JARDIM ECOLÓGICO: O PAISAGISMO COMO ESTRATÉGIA DE SENSIBILIZAÇÃO AMBIENTAL
}

\author{
ECOLOGICAL GARDEN: THE LANDSCAPE AS STRATEGY \\ FOR ENVIRONMENTAL AWARENESS
}

Júlio Bittencourt da Silveira Júnior* Cadidja Coutinho** Raquel Ruppenthal ${ }^{* *}$

\begin{abstract}
RESUMO:
A gestão sustentável dos resíduos constitui um dos princípiọs da Educação Ambiental, pautada na formação de atitudes e comportamentos ecologicamente orientados. Nesta perspectiva, o presente trabalho, vinculado ao projeto "Mobilização Universitária, Todos contra o Aedes e à Favor do Meio Ambiente", de uma universidade de Santiago/RS propôs a utilização de Jardins Ecológicos como ferramenta multiplicadora de informações sobre sưstentabilidade, com o intuito de sensibilizar e estimular a participação da comunidade escolar na proteção ao meio ambiente e na redução dos focos para o desenvolvimento do Aedes aegypti no município. A metodologia consistiu em propiciar aos alunos do ensino fundamental $\left(5^{\circ}\right.$ ao $9^{\circ}$ ano $)$ de escolas públicas municipais uma capacitação acerca das questões ambientais, através de oficinas teóricas/práticas, com a elaboração de jardins com materiais destinados ao descarte. Durante a realização da atividade, observou-se o interesse dos alunos e do corpo docente, e o caráter multiplicador do projeto.
\end{abstract}

Palavras-chave: Aedes aegypti; Sustentabilidade; Educação Ambiental; Redução de Vetores.

\begin{abstract}
:
The sustainable management of waste is one of the principles of Environmental Education and it is based on education for ecological attitude and behaviour. Thus, this study aims to present the project "University. Mobilization, all Against Aedes and in Favour of the Environment", developed at a university, in Santiago, RS. The objective of this project was to use Ecological Gardens as a multiplier tool for providing sustainability information to the school community in order to sensitize and stimulate them to protect the environment in order to reduce the outbreaks of Aedes aegypti. The methodology consisted of providing education on environmental issues to elementary school students (5th to 9th grade) of municipal public schools. It was carried out through theoretical and practical workshops in which was possible to create gardens with materials destined for disposal. During the activities, it was observed the students and faculty members' interest as well as the the multiplier effect of the project.
\end{abstract}

Keywords: Aedes aegypti; Sustainability; Environmental Education; Reduction of Vectors. 


\section{Introdução}

Contemporaneamente, diferentes meios de comunicação repercutem as problemáticas associadas à saúde pública e às questões ambientais, principalmente no que se refere às doenças causadas por arbovírus e suas correlações com o saneamento básico. Em consequência da divulgação de informações, surgem movimentos que instigam a conscientização da população.

Nesse sentido, observa-se a mobilização das lideranças e da sociedade civil na busca por ações voltadas ao meio ambiente, seja através de legislação específica em torno de problemáticas locais, programas governamentais, ou os diversos empreendimentos de grupos, associações e movimentos ecológicos (CARVALHO, 2012; SANTANA et al., 2013; PEREIRA et al., 2013), visando produzir a transformação de hábitos e atitudes. Essas ações normalmente se dão em torno de problemáticas ambientais.

A incursão da Educação Ambiental (EA) nos espaços formais de aprendizagem, por docentes e/ou grupos organizados que visam a sensibilização e o incentivo à tomada de decisões que vão contra a mercantilização dos recursos naturais por atacado, são importantes no processo de desenvolvimento humano. Em virtude de que a demanda exacerbada por valências naturais tende a se concretizar de maneira grave e preocupante, em um compasso apressado (PINTO; ZACARIAS, 2009), é urgente que se discutam os ideais de consumo.

A EA vem evoluindo enquanto espaço para o conhecimento e tornando-se um mecanismo através do qual é possível despertar na população a consciência crítica de suas ações, assim como discutir a importância da preservação do ambiente natural, compartilhado por todos os seres. No que concerne ao processo educativo, a EA tem sido uma importante intercessora entre a educação, o meio ambiente e a saúde pública, debatendo os problemas gerados pela crise ecológica e produzindo mudanças de paradigmas que visam construir as bases do conhecimento ecológico nesta e nas futuras gerações (CARVALHO, 2012).

Não menos importante, as inovações tecnológicas, iniciadas com a revolução industrial, levaram a uma rápida alteração da matéria-prima utilizada para produzir materiais. O predomínio de materiais descartáveis acabou por desenvolver complexos hábitos sociais na humanidade, e, concomitante a eles, diversos problemas ambientais, fazendo-se necessária a política dos 5 R's da sustentabilidade (Reduzir, Reutilizar, Reciclar, Repensar e Recusar) (MARTINS, 2013). A cultura do consumismo, aliada ao descarte irresponsável dos resíduos, está diretamente vinculada a problemas de saúde pública, como é o caso das doenças relacionadas à proliferação de mosquitos.

A partir disso, o presente trabalho está vinculado ao projeto já encerrado (2016-2018) "Mobilização Universitária, Todos contra o Aedes e à Favor do Meio Ambiente", da Universidade Regional Integrada do Alto Uruguai e das Missões na cidade de Santiago/RS. Tratase de um projeto que propôs a utilização de Jardins Ecológicos como ferramenta multiplicadora de informações sobre sustentabilidade, com o intuito de sensibilizar e estimular a participação da comunidade escolar na proteção ao meio ambiente, bem como a redução dos focos para o desenvolvimento do Aedes aegypti no município de Santiago/RS. O trabalho visou a integração entre a comunidade escolar e a Universidade numa visão extensionista, e a ligação entre o conhecimento curricular e a formação de valores e atitudes ambientais.

\section{A Educação Ambiental como catalisadora de ações}

Sabe-se que a inserção da EA na esfera educativa, de forma transversal e interdisciplinar, vem se tornando um consenso para a ligação entre o conhecimento e a formação de atitudes e sensibilidades ambientais (CARVALHO, 2012). Da mesma maneira, a EA permite o estudo e a ação sobre o meio de maneira holística, não-fragmentada e compreendendo o ambiente como um todo, inter-relacionado $\mathrm{e}$ complexo (MORIN, 2011).

Zitzke (2002) também reforça a necessidade de desenvolver um projeto político pedagógico aprimorado, que estimule o desenvolvimento da capacidade crítica, de modo que o cidadão tenha consciência de sua realidade social e ambiental, para que possa se posicionar frente ao cenário global atual. A construção desse ideal só pode ser obtida mediante um pensamento global, integrador e complexo (MORIN, 2011).

Nesse processo, as ações educativas desempenham um papel fundamental na constituição de um ambiente de aprendizagem social e individual, que promova a formação do sujeito humano, com novos pensamentos, atitudes e sensibilidades ambientais (MELO, 2007; CATHARINO, 2007; TEGLIEBER，2007; CASSEB; TRUFEM， 2009; CARVALHO, 2012).

Se o objetivo maior da EA é promover uma mudança de comportamentos que contribua na transição para o desenvolvimento sustentável, importa que os novos comportamentos sejam desenvolvidos e exercitados no ambiente imediato, que é a escola. Ao vivenciar situações reais, em que as mais diversas variáveis e os conflitos apareçam e tenham que ser trabalhados em uma atividade democrática, progressiva e dinâmica, fundamentada pela práxis e resultando na real redução dos impactos causados (ANDRADE, 2000), alcança-se um nível profundo de consciência ambiental.

Cerati e Lazarini (2009) relatam que a consciência crítica pode ser despertada por meio da EA, que tem como desafio promover a mudança de valores, posturas e atitudes, integrando ações aos aspectos ecológicos, políticos, culturais e éticos.

Dessa forma, ao conceder ênfase para a temática ambiental, juntamente com o trabalho paisagista, é possível integrar ações de aspectos ecológicos, culturais e econômicos. Justifica-se a união entre EA e o paisagismo, pois este representa uma arte ou uma técnica de elaborar um projeto, planejar, gerir e preservar determinado local, criando novas noções de beleza e possibilidades de utilização variadas.

Reunir o paisagismo com a EA foi a estratégia utilizada para promover a consciência necessária na redução da proliferação de mosquitos. Deste modo, 
desenvolver atividades práticas diferenciadas de cunho extensionista significa contribuir para a consolidação teórico-metodológica da universidade como espaço político de produção e apropriação social e democrática de conhecimentos (TOZONI REIS, 2003), contribuindo para a articulação da universidade com a comunidade, na construção de uma sociedade mais justa e sustentável.

\section{O Aedes aegypti}

O Aedes aegypti (LINNAEUS, 1762) é um mosquito originário do velho mundo, provavelmente da região nordeste do continente africano. Chegou ao Brasil no período colonial no século XVI, na era das grandes navegações, junto com o transporte de mercadorias e o tráfico de escravos. Considera-se que as superpopulações das embarcações foram fatores decisivos para que a espécie chegasse em contingente suficiente para uma potencial colonização do novo mundo (BRYANT et al., 2007; IOC/FIOCRUZ, 2016).

Sendo cosmopolita, o culicídeo geralmente ocorre em regiões tropicais e subtropicais, compreendidas entre as latitudes $45^{\circ} \mathrm{N}$ e $35^{\circ} \mathrm{S}$. Também podem ocorrer fora dessas regiões, porém, dentro das zonas isotermais de $20^{\circ} \mathrm{C}$. No Brasil, tem sua distribuição associada a grandes aglomerações humanas e está sempre próximo ou no interior das residências. Dificilmente é encontrado em ambientes semi-silvestres ou onde a população humana é mais rarefeita.

Como todos os mosquitos da família Culicidade, o A. aegypti possui metamorfose completa, passando pelas fases de ovo, larva, pupa e adulto. É importante ressaltar que as observações sobre a biologia desta espécie são obtidas principalmente a partir de estudos em laboratório, e podem não refletir o padrão de comportamento em condições reais, uma vez que existem evidências de variações populacionais. Os fatores climáticos que influenciam diretamente as atividades desses mosquitos são, especialmente, variações térmicas e pluviométricas.

Embora raramente possa ser encontrado em recipientes naturais, como ocos de árvore, bromélias e internódios de bambu, os criadouros mais favoráveis para a proliferação do $A$. aegypti são recipientes artificiais abandonados a céu aberto, como pneus, latas, vidros, cacos de garrafa, pratos de vasos, xaxins, vasos de cemitério, piscinas e lagos artificiais abandonados, além de caixas d'água, tonéis, latões e cisternas destampadas ou mal tampadas. Ou seja, condições relacionadas a ocupações/aglomerações humanas.

$\mathrm{O} A$. aegypti é o principal vetor de doenças como a Dengue, Chikungunya e Zika nas Américas. O Brasil vem realizando campanhas de combate ao $A$. aegypti desde o início do século $\mathrm{XX}$, quando as medidas de controle chegaram a ser eficazes e o país foi considerado livre do mosquito em 1958, pela Organização Mundial da Saúde (OMS). Porém, a erradicação não ocorreu de maneira uniforme em todo o bloco continental, criando condições favoráveis ao retorno do A. aegypti em território nacional.

As campanhas contra os arbovírus foram intensificadas desde 2014, ano em que foram relatados diversos surtos, tanto de Zika, sendo o Brasil o primeiro país do continente a relatar casos de uma epidemia. Também quanto à Chikungunya, que, apesar de serem vírus novos no continente (Zika e Chikungunya), já são conhecidos em regiões orientais. Vasconcelos (2015) relaciona a entrada das novas doenças no Brasil, com a Copa do Mundo, de 2014.

Observa-se o esforço das esferas políticas federais, estaduais e municipais, em âmbito de conscientizar a população de que o controle das infestações será efetivo apenas se houver mobilização da sociedade como um todo. Além de campanhas de informação e monitoramento, os municípios têm efetuado o Levantamento De Índice Rápido para $A$. aegypti (LIRAa). O LIRAa permite um diagnóstico rápido da situação entomológica de um município, para direcionamento das ações de controle do vetor e de educação em saúde.

As vantagens da utilização deste tipo de ferramenta são a possibilidade de identificar os criadouros predominantes, bem como descrever o nível de infestação do município. Para tal, a cidade é dividida em grupos e, em cada grupo, um número predefinido de imóveis são arrolados. Os grupos (ou estratos) de infestação, inferiores a $1 \%$, são considerados em situação satisfatória, de $1 \%$ a $3,9 \%$ caracteriza-se uma situação de alerta, e, quando superiores a $4 \%$, entende-se que há risco de surto de dengue na região.

O município de Santiago/RS realizou o LIRAa enquanto o projeto estava em andamento e o resultado obtido foi o de alerta, reforçando a importância da realização de atividades e projetos de extensão com o objetivo de conscientizar a comunidade. $\mathrm{Na}$ sequência, relatam-se as atividades ofertadas por meio do projeto de extensão, bem como os resultados observados como um todo, seja através da integração entre escola e universidade ou de campanhas desempenhadas em conjunto com as Secretarias de Saúde e Meio Ambiente da cidade.

\section{Percurso metodológico}

Em razão da rápida disseminação de arboviroses na região noroeste do estado do Rio Grande do Sul, e considerando-se que já foram detectados focos do mosquito em vários bairros do município de Santiago/RS, o presente trabalho prestou apoio à Secretaria Municipal de Saúde de Santiago/RS. A colaboração para a execução do programa de combate ao A. aegypti se deu através de recurso humanos para as atividades e para o processamento das informações obtidas durante as campanhas de vistoria às residências.

As atividades consistiram em oficinas teóricas e práticas, com a elaboração dos Jardins Ecológicos, um modelo adaptado de jardim vertical, ofertada para alunos do ensino fundamental $\left(5^{\circ}\right.$ ao $9^{\circ}$ ano) de escolas públicas municipais. As oficinas foram organizadas utilizando-se métodos lúdicos, desenhos, animações, dinâmicas, bem como aulas práticas e experimentais, em concomitância e transversalmente ao conteúdo programático da série/ano correspondente.

Os materiais utilizados na construção dos jardins provinham de processos de descarte, da família 
dos alunos, da própria escola ou da comunidade, com o objetivo de reutilizar materiais, diminuir o descarte de resíduos e, principalmente, reduzir a eliminação de objetos com potencial de servir de criadouro do mosquito $A$. aegypti.

Antes da execução das atividades propostas pelas oficinas, os alunos foram convidados a responder um questionário de identificação das concepções prévias sobre o tema (Figura 1). A aplicação de questionário justifica-se em função de avaliar a efetividade das atividades aplicadas. As respostas foram analisadas de acordo com Minayo (2014), em uma abordagem qualitativa e representação numérica dos dados.

Figura 1 - Questionário de identificação das concepções prévias dos participantes da pesquisa.
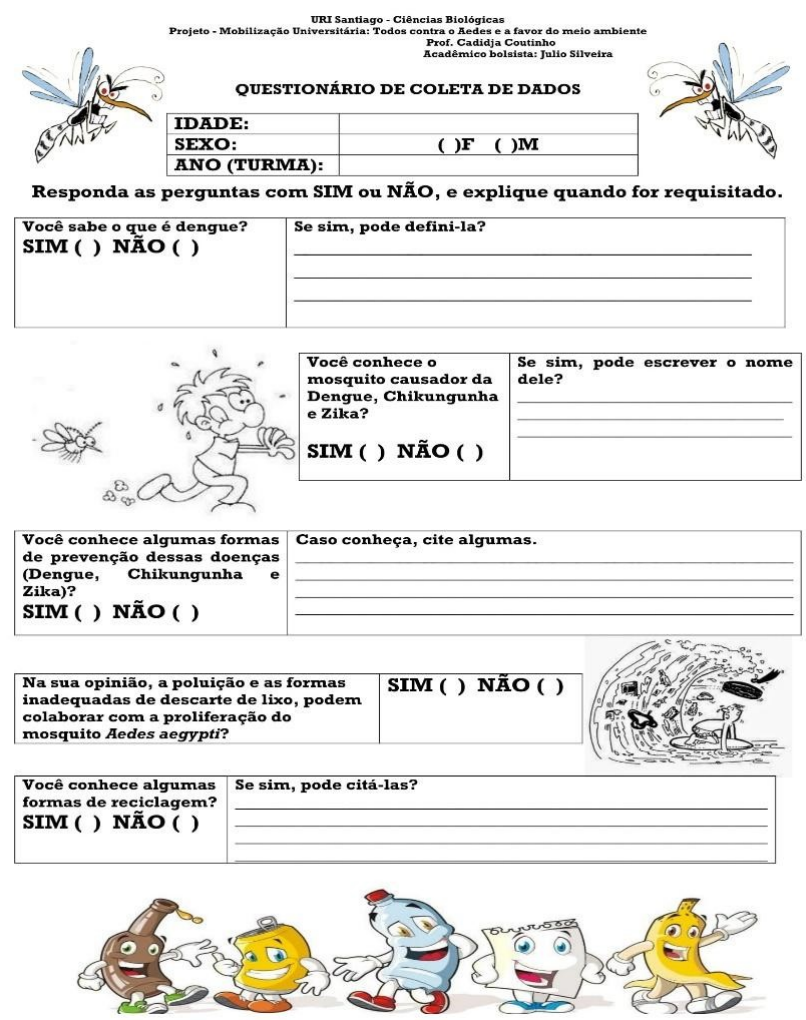

Fonte: Autores, 2019.

\section{Relatos e reflexões da práxis}

As atividades do trabalho desenvolveram-se em escolas da rede municipal e foram divididas em três etapas. A primeira etapa foi a aplicação dos questionários para coleta inicial de dados, seguida de uma palestra interativa sobre o tema central da atividade (Figura 2).

Figura 2 - Palestra interativa.

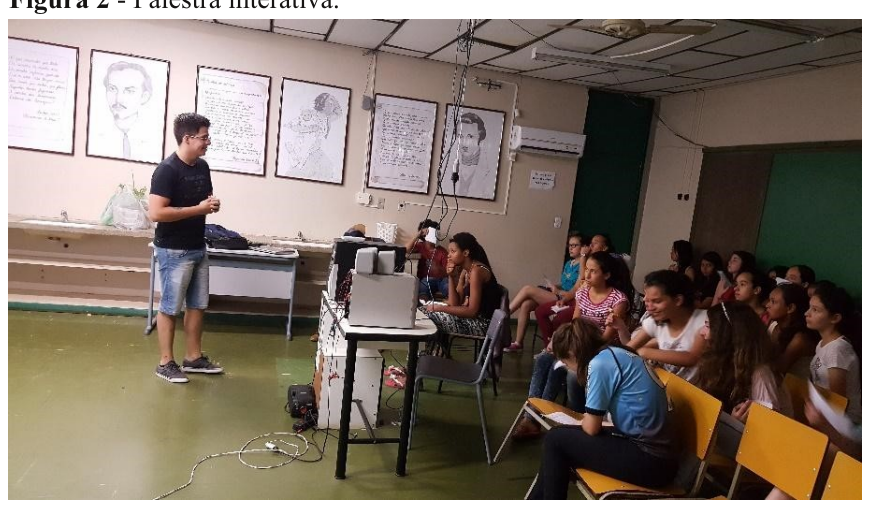

Fonte: Autores, 2019
Durante a etapa final, ocorreu a implementação da prática de sensibilização proposta pelo presente trabalho (Figura 3), onde, utilizando-se materiais recicláveis, plantas medicinais e ornamentais, foram confeccionados os Jardins Ecológicos nas escolas.

Figura 3 - Oficina e construção de Jardins Ecológicos.

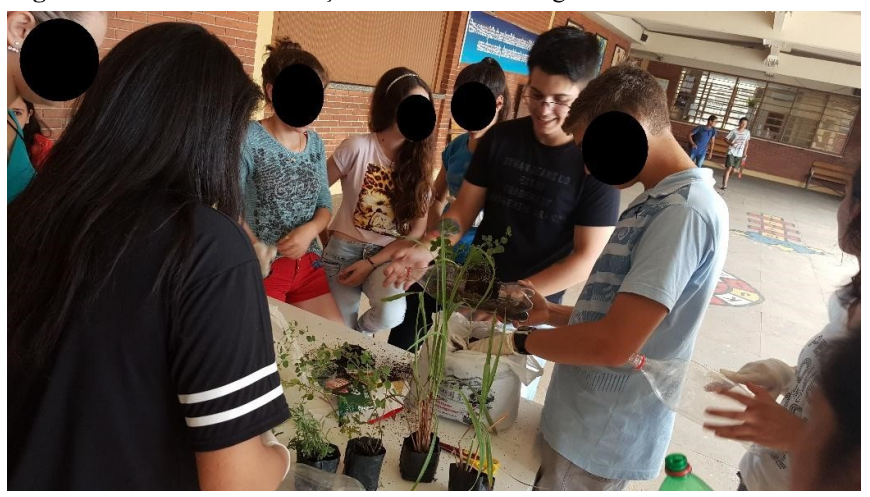

Fonte: Autores, 2019.

Do ponto de vista pedagógico, pode-se considerar que a execução das atividades extensionistas em escolas são de suma importância, pois através delas são fornecidas informações relevantes sobre os mais variados temas, incluindo a discussão de assuntos e a sua aplicação na vida em comunidade. $\mathrm{Na}$ ação aqui relatada, a reutilização de materiais destinados ao descarte conduziu discentes, corpo docente e funcionários envolvidos a realizar questionamentos pertinentes ao tema proposto. Dessa forma, pode-se inferir que, apesar de eficazes, campanhas baseadas exclusivamente em discursos podem não ser suficientes no processo de sensibilização da comunidade.

A escola precisa construir um processo em que os alunos dominem concepções e destrezas essenciais para a vida moderna, no sentido da proteção do meio ambiente e da biodiversidade (SOARES JÚNIOR et al., 2012), por meio de um processo educativo emancipatório. De acordo de Sauvé (2005), a EA não pode ser considerada uma "forma" de educação ou uma "ferramenta" para resolução da problemática ambiental. Deve ser vista como um princípio essencial da educação, uma rede de interações baseada na relação com o meio em que vivemos, com essa "casa de vida" compartilhada.

A temática de reciclagem de materiais é abordada em diferentes contextos na

pesquisa em EA (por exemplo, BASTIANELLO, 2005; ASSAD et al., 2011), mostrando ser um mecanismo para inserção de conceitos (como padrões de consumo, volume do lixo, desperdício, disposição no ambiente e coleta seletiva), do espírito crítico em relação à exploração dos recursos naturais, e principalmente a formação de uma cidadania ambiental. Guadagnin (2010 apud ASSAD et al., 2011, p. 54) afirma que "ao minimizar a produção dos resíduos comuns por meio da segregação daqueles passíveis de reciclagem, há a redução da quantidade disposta desses resíduos no meio ambiente".

Os resíduos, quando coletados e tratados inadequadamente, provocam efeitos diretos e indiretos na saúde da população e contribuem para a degradação do ambiente. Segundo o Conselho Nacional do Meio 
Ambiente (CONAMA), em sua Resolução n. ${ }^{\circ}$ 5/93, artigo $1^{\circ}, \mathrm{I}$, os resíduos podem resultar de atividade da comunidade de origem industrial, doméstica, hospitalar, comercial, agrícola, de serviços e de varrição. Em relação aos resíduos sólidos domésticos, especificamente, Ferreira (2006) afirma que os principais componentes são restos alimentares, papel, vidro, pano, madeira, metal, osso e material ocioso (terra, por exemplo), gerados pelas atividades cotidianas dos lares.

Atualmente, o processo de destinação dos resíduos sólidos domésticos é um problema de responsabilidade de âmbito individual, da comunidade e dos poderes públicos. A responsabilidade assume uma dimensão individual na medida em que cada cidadão é responsável por depositar seus resíduos domésticos em local adequado (OLIVEIRA et al., 2009). Diante dessa premissa, justifica-se a elaboração e execução de oficinas pedagógicas que abordam essa problemática e seus desdobramentos, bem como ações de extensão.

Após a fase final do trabalho nas escolas, deu-se início ao processo de organização e análise do questionário apresentado na Figura 1, cujos resultados estão descritos na Figura 4.

Figura 4 - Respostas apresentadas ao questionário de coleta de dados

\section{ANÁLISE DE DADOS QUANTITATIVOS}

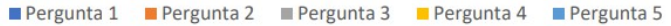

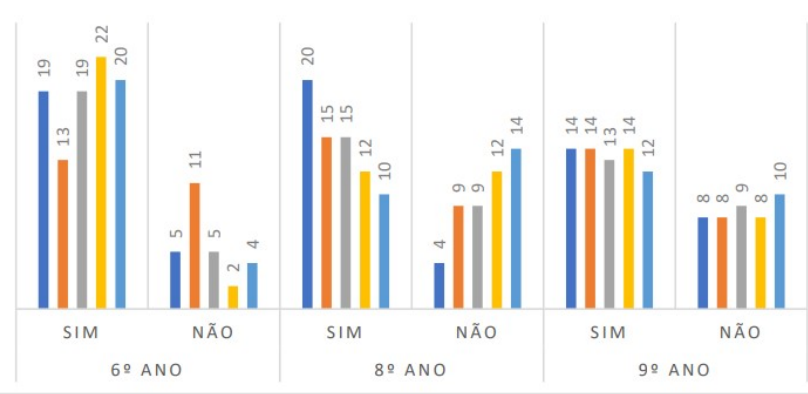

Fonte: Autores, 2019.

Com a análise de dados, observaram-se fatores preocupantes em todas as turmas, sendo estes: (i) A maioria dos alunos de $6^{\circ}$ ano afirma ter conhecimento sobre o que é dengue, muito embora não sabia ou não quis descrever as características básicas da doença; (ii) Quase $50 \%$ dos educandos, em um contexto geral, não conhecem o A. aegypti; (iii) $67 \%$ do total de discentes diz ter conhecimento sobre as formas de prevenção da Dengue, Zika e Chikungunya, ainda que $82 \%$ dos entrevistados se abstiveram ou não forneceram informações concretas; (iv) As turmas de $8^{\circ}$ e $9^{\circ}$ anos, respectivamente $50 \%$ e $40 \%$ dos alunos, afirmam que a poluição e outras formas inadequadas de descarte de lixo não colaboram com a proliferação do $A$. aegypti; (v) $60 \%$ dos discentes que optaram por responder ao questionário afirmaram ter conhecimento sobre algumas formas de reciclagem, contudo, $77 \%$ não souberam listar ao menos exemplo de reciclagem na parte descritiva da questão.

Em outro recorte dos dados, ao analisar os dados das turmas de $7^{\circ}$ ano das escolas, pode-se perceber que a grande maioria também afirma ter conhecimento sobre a dengue, muito embora não conheça o mosquito causador da doença. Numa escola localizada na região periférica da cidade, percebe-se que a porção majoritária de alunos considera que a poluição e as formas inadequadas de materiais são grandes colaboradores para o aumento da proliferação de doenças causadas por arbovírus. Notou-se que grande parte dos alunos de uma escola periférica participante não conhecia o mosquito $A$. aegypti, sendo a maioria das respostas do questionário marcada negativamente.

Cada questão permitia complementar as respostas afirmativas com informações adicionais. Essas descrições foram analisadas e organizadas em categorias. Destacou-se o resultado de uma das escolas participantes para a questão 1 . Dos participantes dessa escola, 53 afirmam ser uma doença; 29 afirmam ser um mosquito (29); e 6 indicam que é um vírus. Tal dado demonstra-se preocupante, se for considerado que 32\% dos questionados consideram Dengue um mosquito.

Com a análise dos questionários, nota-se que há uma demanda por processos inserção da alfabetização científica, ou seja, conhecimentos conceituais aplicados na compreensão da realidade e, principalmente, para embasar a mudança de atitudes. Quadros (2007) reforça que, através da EA, podem-se unir as mais diversas áreas do conhecimento. Nesse sentido, a EA apresenta-se como facilitadora e contextualizadora, uma vez que possibilita abordar diversas temáticas de maneira transversal, além de apresentar a capacidade de libertar os discentes do senso comum e expandir seus horizontes cognitivos.

A relação meio ambiente e homem constitui a base da EA, pautada na formação de valores éticos, atitudes e comportamentos ecologicamente orientados, na busca por alternativas que visam construir novas maneiras dos grupos sociais se relacionarem com a natureza (CARVALHO, 2012). Esta mudança de comportamentos que a EA objetiva contribui para o desenvolvimento sustentável, que pode ser exercitado desde o início da formação do indivíduo no ambiente imediato que é a escola.

Neste contexto, o estímulo ao cultivo de espécies vegetais em Jardins Ecológicos, como realizados por meio deste projeto de extensão, empregando materiais reutilizáveis por alunos de ensino fundamental, visa construir práticas de convívio com o meio ambiente, empregando materiais reutilizáveis e reduzindo os danos que os mesmos causariam caso fossem descartados diretamente na natureza. Além de contribuir para o desenvolvimento de atitudes ambientais, favorece a utilização de conceitos e conhecimentos em contextos práticos ou aplicados na solução de problemas do cotidiano, como no caso das doenças transmitidas pelo A. aegypti.

\section{Considerações Finais}

Pode-se concluir que os resultados decorrentes deste trabalho, ao longo de dois anos, possibilitaram o estabelecimento de interfaces entre a comunidade escolar e a universidade, partindo de uma visão extensionista, bem como na sensibilização dos alunos do ensino fundamental, no que tange aos aspectos ecológicos, sociais e nos mecanismos de controle aos vetores de doenças endêmicas. Espera-se ainda que a atividade tenha formado multiplicadores de 
informações, para que a ideia da mesma seja expandida para além de seus limites logísticos.

Evitando generalizações a partir dos dados encontrados, é preciso considerar o défice do trabalho em relação à realização das atividades exclusivamente em escolas municipais urbanas, centrais e periféricas. Em contraponto, a escolha baseou-se em indicativos da Secretaria Municipal de Saúde para focos do mosquito causador das doenças supracitadas.

Numa perspectiva futura, espera-se abranger um número maior de escolas, estabelecer parcerias com a rede estadual de ensino, assim como dirigir-se às escolas rurais.

Por fim, é preciso destacar que a sensibilização ambiental exige um fluxo contínuo e reincidente de ações em prol do meio ambiente para que hábitos ecossustentáveis sejam estabelecidos. As ações deste projeto podem servir de inspiração e continuidade para o desenvolvimento de um processo de formação ambiental.

\section{Referências:}

ANDRADE, D. F. Implementação da Educação Ambiental em escolas: uma reflexão. Fundação Universidade Federal do Rio Grande. Revista Eletrônica do

Mestrado em Educação Ambiental, v.4, 2000.

ASSAD, L. G.; BERARDINELLI, L. M. M.; DA SILVA, D. P. P.; DE OLIVEIRA JUNIOR, A. A. B.; RODRIGUES, T. G. Reciclagem de papel: uma experiência de ensino, extensão e pesquisa. Interagir: pensando a extensão, n. 16, p. 53-57, 2011 .

BASTIANELLO, S. F. Desenvolvimento de embalagens a partir de papel reciclado reforçado com fibras naturais: uma proposta ambientalmente amigável. Dissertacão (Mestrado em Saúde e Meio Ambiente) - Universidade da Região de Joinville, 2005.

BRYANT, J. E.; HOLMES, E. C.; BARRETT, A. D. T. Out of Africa: A Molecular Perspective on the Introduction of Yellow Fever Virus into the Americas. PLoSPathog, v.3, n.5, p.75, 2007.

CARVALHO, I. C. M. Educação ambiental: a formação do sujeito ecológico. 6. ed. São Paulo: Cortez, 2012.

CASSEB, D.C.; TRUFEM, S.F.B. Educação ambiental em escolas da rede pública na área da Represa de Guarapiranga, São Paulo. 2009. Disponível em: http://www.saomarcostatuape.com.br/portal2/pesquisaEmDe bate/docs/pesquisaEmDebte especial1/artigo 17.pdf \&gt. Acesso em: 20 fev. 2019.

CATHARINO, R. C. A. Imagética dos livros didáticos nas relacões de gênero e educacão ambiental. Dissertacão (Mestrado em Educação) - Universidade Federal de Mato Grosso, Cuiabá, 2007.

CERATI, T. M.; LAZARINI, R. A. de M. A Pesquisa-ação em Educação ambiental: uma experiência no entorno de uma unidade de conservação urbana. Ciência \& Educação, v. 15, n. 2 , p. $383-92,2009$.

FERREIRA, L. Ideias para uma sociologia da questão ambiental no Brasil. São Paulo: Annablume, 2006. 112p.
IOC/FIOCRUZ. Dengue vírus e vetor. Disponível em: $<$ http://www.ioc.fiocruz.br/dengue/textos/longatraje.htm 1>. Acesso em: 25 fev. 2019.

MARTINS, M. C.; FROTA, P. R. O. Educação Ambiental: a diversidade de um paradigma. Criciúma: UNESC, 2013.

MELO, G. P. Noções práticas de educação ambiental para professores e outros agentes multiplicadores. Instituto Brasileiro do Meio Ambiente e dos Recursos Naturais Renováveis: Superintendência do IBAMA na Paraíba. João Pessoa. 2007.

MINAYO, M. C. S. O desafio do conhecimento. 14. ed. São Paulo: Hucitec, 2014.

\section{MORIN, E. Os sete saberes necessários à educação do} futuro. São Paulo: Cortez. 2011.

OLIVEIRA, A. C. M. A.; MAZZARINO, J. M.; TURATTI, L. A responsabilidade na destinação dos resíduos sólidos domésticos: análise de discurso dos cidadãos no município de Lajeado. Porto Alegre. Anais... Porto Alegre: X Salão de Iniciação Científica. PUCRS, p. 2425 - 2427, 2009.

PINTO, V. P. S.; ZACARIAS, R. Crise ambiental: adaptar ou transformar? As diferentes concepções de educação ambiental diante deste dilema. Educação em Foco, n. 14, v. 02, 2009.

PEREIRA, C. C.; SILVA, F. K.; RICKEN, I.; MARCOMIN, F. E. Percepção e Sensibilização Ambiental como instrumentos à Educação Ambiental. Revista Eletrônica do Mestrado em Educação. Ambiental, v. 30, n.2, p. 86 - 106, 2013.

QUADROS, A. Educação Ambiental: Iniciativas Populares e Cidadania. Santa Maria, 2007. Disponível em:

$<$ http://jararaca.ufsm.br/websites/unidadedeapoio/download/ alessandra.pdf $>$ Acesso em: 08 fev. 2019.

SANTANA, E. S.; LIMA, E. C.; SANTOS, B. V. J. Práticas de educação ambiental projeto: escola e comunidade cuidando do meio ambiente. Cadernos de Graduação Ciências Humanas e Sociais. Aracaju, v. 1, n.16, p. 59-71, 2013.

SOARES JUNIOR, M. P.; PEREIRA JUNIOR, E. B.; SANTOS, F. G. B.; NETO, P. A.; SAMPAIO, R. N.; BORGES, M. G. B.; FERREIRA, R. T. F. V. Educação ambiental: um desafio à sustentabilidade sócio ambiental. RBGA (Pombal - PB - Brasil), v.6, n.1, p. 18 - 34, 2012.

TAGLIEBER, J.E. Uma pedagogia para a dimensão ambiental na educação. In: GUERRA, Antônio Fernando S.; TAGLIEBER, José Erno. (Orgs.). Educação Ambiental: fundamentos, práticas e desafios. Itajaí: Universidade do Vale do Itajaí, 2007.

TOZONI REIS, M. F. C. Pesquisa em Educação Ambiental na Universidade: produção de conhecimentos e ação educativa. In: TALAMONI, Jandira, L. B.; SAMPAIO, Aloíso Costa. Educação Ambiental: da prática pedagógica à cidadania. São Paulo: Escrituras Editoras, 2003.

VASCONCELOS, P. Doença pelo vírus Zika: um novo problema emergente nas Américas?. Revista PanAmazônica de Saúde, n.6, p.9-10, 2015.

ZITZKE, V. A. Educação Ambiental e Ecodesenvolvimento. Revista Eletrônica do Mestrado em Educação Ambiental. Fundação Universidade Federal do Rio Grande, v. $9,2002$. 